\title{
El sudor del Sol y las lágrimas de la Luna: La metalurgia del oro y de la plata en el Antiguo Perú
}

\author{
Cruz Martinez de la Torre *
}

\begin{abstract}
RESUMEN
El oro y la plata fueron los metales cuyo hallazgo en el continente americano despertó grandes espectativas de riqueza en la menta de los primeros conquistadores, incluso antes de su descubrimiento. Los cronistas aportan abundantes noticias no sólo sobre las fabulosas riquezas metálicas que poseía el Perú sino, incluso, sobre los diferentes procesos tecnológicos que tuvieron lugar desde la extracción de ambos metales hasta su transformación en objetos suntuarios, asi como sobre el valor y significado que tuvieron el oro y la plata en el Perú prehispánico.
\end{abstract}

\section{ABSTRACT}

The finding of gold and silver in the american continent raised great expectations of wealth among the conquerors. The chronicles provide a detailed account not only of the fabulous richness in metals of Peru, but also of the technological process of extraction and of the transformation of these metals in luxury objects. Through them we learn about the simbolic meaning of gold and silver in prehispanic Peru.

El oro y la plata fueron utilizados por los antiguos orfebres peruanos para crear una amplia gama de objetos, de tipo ceremonial y suntuario, relacionados todos ellos estrechamiente con una determinada ideología religiosa y política.

Tal como sucede con las primeras noticias procedentes de otras regiones americanas, los documentos relativos a la conquista del Perú abundan en

* Departamento de Historia del Arte. UNED. 
sus fabulosas riquezas metálicas, exagerándose en algunas ocasiones los datos debido, entre otras razones, a que no habia mineros de oficio ni entre los conquistadores ni entre los cronistas o entre los primeros colonizadores.

La desmentida fiebre por encontrar estos metales, que en un primer momento entregaron los gobernantes incas de estas tierras a los españoles en señal de paz y como símbolo de amistad, condujo a relaciones de dominio de éstos sobre los indígenas que en ocasiones derivaron en los más terribles episodios de la Conquista, obligándoles así a esconder sus metales preciosos (Inca Garcilaso 1943:10) —considerados como dones celestiales que articulaban en el mundo de los seres vivos con el de las divinidades y fuerzas supranaturales - y a utilizar en última instancia algunos de ellos como productiva moneda de cambio destinada a salvar la vida de sus gobernantes, tal como ocurrió en el frustado intento por librar de la muerte al inca Atahuallpa.

Pese a las aludidas posibles imprecisiones de los cronistas, es obvio que la cantidad de dichos metales preciosos existente en el imperio inca era inmensa, hecho de que ponen de manifiesto las reveladoras descripcions que sobre el Coricancha, el recinto de los dioses de la ciudad del Cuzco, nos aportan los cronistas Cieza de León y el Inca Garcilaso de la Vega. El primero (1985: 97-99) relata que "Tenía este templo en circuito más de cuatrocientos pasos, todo cercado de una muralla fuerte, labrado todo el edificio de cantería muy excelente de fina piedra muy bien puesta y asentada, y algunas piedras eran muy grandes y soberbias (...) Había muchas puertas y las portadas muy bien labradas; a media pared, una cinta de oro de dos palmos de ancho y cuatro dedos de altor. Las portadas y puertas estaban chapadas con planchas de este metal. Más adentro estaban cuatro casas no muy grandes labradas desta manera (...) En la una destas casas, que era la más rica, estaba la figura del sol, muy grande, hecha de oro, obrada muy primamente, engastonada en muchas piedras ricas; estaban en aquella algunos de los bultos de los Incas pasados que habían reinado en el Cuzco, con gran multitud de tesoros".

Sobre su maravilloso jardín, fabricado todo él en oro y plata, escribe el segundo (1943: 79-80): "havía muchas yerbas y flores de diversas suertes, muchas plantas menores, muchos árboles mayores, muchos animales chicos y grandes, bravos y domésticos, y savandixas de las que van arrastrando como culebras, lagartos y lagartijas y caracoles, mariposas y pájaros y otras aves mayores del aire, cada cosa puesta en el lugar que más al proprio contrahiziesse a la natural que remedava (...), todo para ornato y mayor majestad de la casa de su Dios el Sol. Que como cada año, a todas las fiestas principales que le hazían le pressentavan tanta plata y oro, lo empleavan todo en adornar su casa, inventando cada día nuevas grandezas, porque todos los 
plateros que havía dedicados para el servicio del Sol no entendían en otra cosa sino en hazer y contrahazer las cosas dichas (...) En suma, no havía en aquella casa cosa alguna de que echar mano para cualquiera ministerio que todo no fuesse de oro y plata, hasta lo que servía de açadas y açadillas para limpiar los jardines. De donde con mucha razón y propiedad llamaron al templo del Sol y a toda la casa Coricancha, que quiere dezir barrio de oro".

En cualquier caso, lo que si resulta evidente es que a partir del contacto entre ambas culturas, y como consecuencia del encuentro de dos universos distintos, se produjo un cambio acerca de la valoración de dichos metales desde una concepción más simbólico religiosa que material -en la que se concebía al oro como una manifestación inequívoca de la divinidad solar y de su fuerza fecundante y a la plata como una prueba del poder de la femenina divinidad lunar - a otra en la que se los consideraba estrictamente como signos de riqueza y de valor material en sí mismos. De esta forma, el oro y la plata, pese a simbolizar para los nativos poderes sobrenaturales, fueron fundidos y convertidos en lingotes para, posteriormente, ser embarcados con destino a España. A pesar de ésto, una pequeña parte de los objetos más relevantes consiguieron salvarse, los cuales, tras su llegada a la metrópoli, fueron entregados al rey o a diversos monasterios y particulares, o bien fueron expuestos para que la corte y todo el pueblo pudiesen apreciar las exóticas y ricas manufacturas de estos pueblos. Posteriormente estos objetos fueron fundidos y su metal reutilizado, o bien pasaron a formar parte de las colecciones que la nobleza u otras personas con educación y recursos solían poseer.

No obstante, pese a las abundantes referencias de los cronistas acerca de las riquezas que guardaba el continente americano, es preciso señalar que éste no fue un continente singularmente metalúrgico, encontrándose la mayor parte del mismo con anterioridad a la Conquista en la etapa conocida con el nombre de Edad de la Piedra. De esta forma (Rovira 1991: 83), mientras que en el Viejo Mundo la metalurgia prehistórica se caracterizó por seguir unas pautas funcionales que partieron del cobre y continuaron con su aleación del bronce hasta llegar al hierro, en Sudamérica, cuna de la metalurgia del Nuevo Mundo, no sólo no se conoció este último metal hasta la llegada de los españoles sino que el cobre y sus aleaciones jugaron un papel bastante secundario, hasta el punto de tenerse que esperar casi hasta el advenimiento del imperio Inca para que la metalurgia del bronce produjera herramientas y armas en mayor cantidad, sin que por ello llegaran nunca a suplantar los utensilios de piedra.

Pese a esta realidad, fueron el oro y la plata, esta última en menor proporción, los materiales que guiaron su evolución tecnológico-metalúrgica, 
pudiéndose afirmar que la América antigua, a pesar de estar matoritariamente inmersa en la Edad de la Piedra, fue un continente de grandes artistas orfebres (Sánchez 1988: 5). Éstos fueron especialistas a tiempo completo altamente cualificados que gozaron en las sociedades urbanas en que trabajaban de un reconocimientos y de un prestigio superior al del resto de los artífices. Este hecho pudo deberse a que se les consideraba los señores del fuego, capaces de transformar a través de él las propiedades específicas de unos materiales de gran valor asociados mágicamente con los dioses (Falchetti 1999: 62) -de ahí los numerosos tabúes que rodearon a sus actividades-, hasta el punto de convertirlos tanto en ofrendas a ellos destinadas como en objetos de lujo para ensalzar el poder de sus dirigentes. Esta poderosa clase social, considerada de origen divino, legitimaba su poder a través de la rica simbología de dichos objetos, los cuales eran utilizados por sus gobernantes tanto durante su vida como después de su muerte. No debemos olvidar que estas manufacturas estuvieron destinadas, en última instancia, a acompañar al difunto en el más allá, dada la importancia que tuvo en todas las culturas americanas la vida de ultratumba.

El hecho de que la muerte fuera tan sólo un acontecimiento que permitía al difunto de alto rango acercarse aún más a su antepasado divino, que era el que, en definitiva, autentificaba el poder de su linaje, dió lugar a la fabricación de complejos y variados ornamentos de rango destinados a formar parte del ajuar funerario, ajuar que nunca ningún personaje importante heredaba de sus antepasados al estar destinado a seguir usándolo tras su muerte. De esta forma, "el oro, caído en gotas del sol o surgido de las venas incandescentes de la tierra, convertido con sabiduría, arte y respeto en mensaje y emblema de los dioses, volvía a la tierra, incorruptible y eterno para continuar el ciclo perdurable de los muertos que siguen viviendo" (Alba 1992: 114).

Con el laboreo del oro tiene lugar el comienzo de la metalurgia americana, fechable hacia comienzos del segundo milenio a.C., si bien tuvo que existir una fase previa de experimentación hasta que se consiguiera la consolidación de los primeros logros. Con posterioridad, será durante el primer milenio a.C. cuando su conocimiento se difunda desde Perú y Bolivia hacia Chile y Argentina, por el sur, y hacia Colombia y el istmo centroamericano a comienzos de nuestra era, por el norte, para continuar irradiándose por México ya hacia finales del primer milenio d.C. (Bray 1991: 58). Su búsqueda consciente hizo que se le rastreara, debido a su fácil maleabilidad, tanto en las entrañas de la tierra como en las arenas de los ríos, iniciándose así el proceso de minería aurífera cuya importacia fue creciendo lentamente desde su aparición a comienzos del Período Formativo con el Horizonte Chavín, entre el 1000 y el 800 a.C. (Petersen 1970: 43), adquiriendo dicho desarrollo su punto culminante durante las culturas que se 
desarrollaron desde el inicio de nuestra era hasta mediados del siglo xvI, tales como la Mochica, la Chimú o la Inca. El hecho de que la actividad minero-metalurgica estuviera enfocada a la elaboración de bienes suntuarios destinados a los dioses y a las élites políticas con ellos relacionados, requería por parte de los mineros la práctica de una serie de ritos de purificación

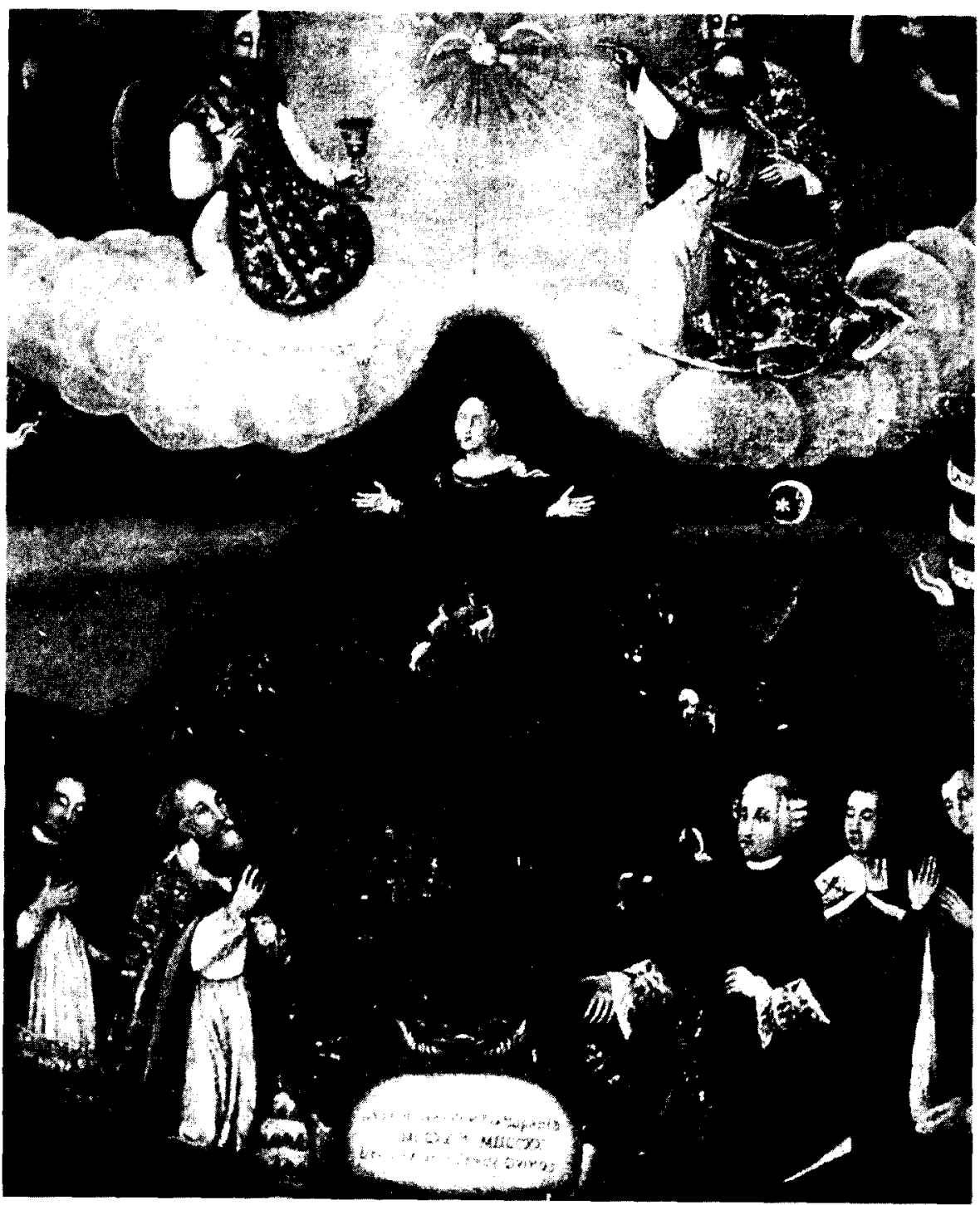

Fig. 1. La Virgen-Cerro. Anónimo. Óleo. Hacia 1765. Museo Nacional de Arte. La Paz. 
previos a la entrada en el seno de la Madre Tierra, al ser considerada ésta una zona sagrada y peligrosa donde los metales, al estar inmersos en ella, participaban de su sacralidad (Barradas 1966: XV). Resulta interesante constatar cómo este culto incaico a la diosa tierra, o Pachamama, se identificó en ocasiones tras la Conquista con el de la Virgen María (Fig. 1).

Si bien el resultado cuantitativo de las extracciones sistemáticas de oro fue variable conforme a si éste se obtenía mediante la explotación de minas subterráneas o a través de ingenios emplazados a tajo abierto, como por ejemplo en el caso del lavado de las arenas de los ríos, en cualquier caso este metal se trabajó siempre en estado nativo y sin refinamiento previo, aún cuando pudiera encontrarse naturalmente aleado con la plata. El fácil hallazgo del oro en estado nativo en los depósitos auríferos situados en ambas vertientes de la cordillera andina, tanto bajo la forma de depósitos filonianos como en yacimientos detríticos, facilitó el desarrollo de su metalurgia. En los primeros el oro se presenta preferenemente en vetas de cuarzo con o sin pirita $u$ otros minerales (Petersen 1970: 44), explotándose, además, en las zonas de oxidación de los afloramientos de vetas auríferas y/o aureo-argentíferas.

Pese a lo que podría parecer, no resulta tarea fácil en la actualidad deslindar donde estuvieron situados los emplazamientos de las primitivas minas indígenas debido a la frecuente superposición de las extracciones coloniales sobre las anteriores y a que tan sólo en muy escasas ocasiones se han encontrado herramientas primitivas que avalen su adscripción a dicha etapa precolombina, tal como sucedió con el hallazgo de la mina cuprífera de Chuquicamata, en el desierto de Atacama en Chile. En ésta se encontró el cadáver de un minero sepultado tras un derrumbe junto con sus herramientas consistentes en dos cestas; un capacho de cuero, un hacha de piedra y varios martillos del mismo material atados a mangos de madera por medio de correas de piel de llama, conservándose en la actualidad todo el conjunto en el Museo de Historia Natural de Nueva York (Petersen 1970: 70).

Este mismo autor señala (1970: 44) que, por norma general, las antiguas minas de oro se ubicaban casi siempre en alturas muy elevadas donde las vetas afloran debido a la erosión glaciar pleistocénica, es decir a unos 5.000 metros de altura o más sobre el nivel del mar, penetrando generalmente los mineros en ellas a una prudente distancia y profundidad por medio de estrechos pozos que, cortando los filones de cuarzo, llegaban hasta donde alcanzaba la luz del día. Por lo que respecta a los depósitos detríticos el oro se presenta en polvo, chispas y pepitas de tamaño variable conforme el transporte fluvial le desgasta y le va alejando de la 
veta de origen. En su opinión (1970: 48) los depósitos auríferos detríticos explotados antiguamente en las provincias de Caraboya y Sandia se dividen en placeres morrénicos y fluvioglaciares, placeres en terrazas fluviales y placeres a nivel de río, siendo siempre preciso para la obtención del metal la derivación hacia una corriente de agua que permita concentrarle por medio de una artesa circular de madera o batea (Fig. 2).

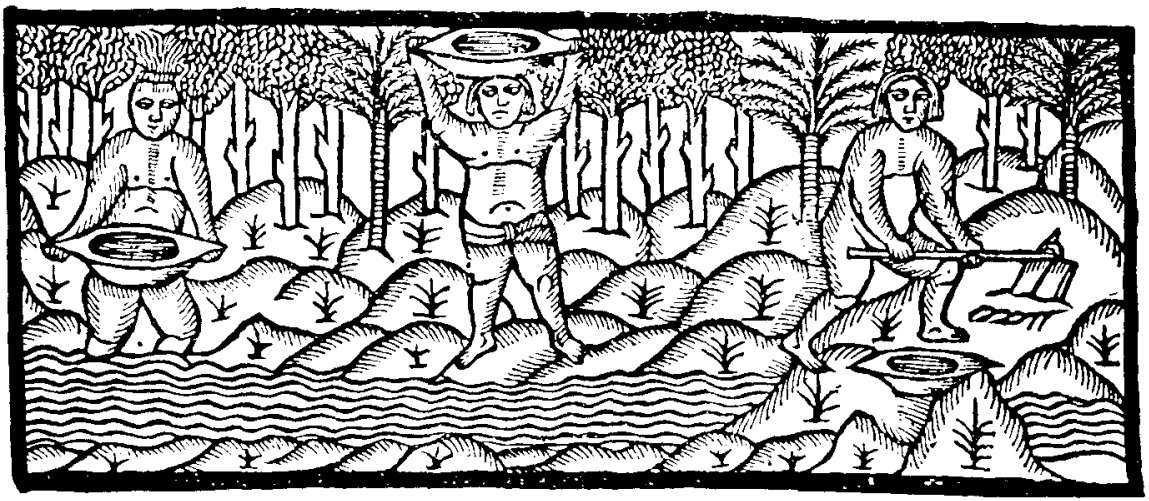

Fig. 2. Lavado del oro. Grabado. Gonzalo Fernández de Oviedo, 1535.

Con posterioridad a la extracción del mineral y su concentración mediante la separación de la mena de la ganga, actividades realizadas ambas a pie de mina, tenía lugar la trituración y molienda de esta última, su transporte y su fundición antes de ser distribuída a los talleres orfebres convertida ya en lingotes o tortas para su futuro trabajo. El proceso de la fundición de la ganga tenía lugar en pequeños hornos de terracota, o guayras, cuyo fuego se avivaba mediante la acción del viento o mediante el soplo de boca de dos o tres hombres que, usando toberas encajadas en cañas, lograban mantener el horno a una temperatura de entre 1100 y 1200 grados centígrados. Respecto a las guayras Cieza (1984: 375) las considera "una invención la más extraña del mundo, y es que antiguamente, como lo ingas fueron tan ingeniosos en algunas partes que les sacaban plata, debía no querer correr con fuelles, como en esta de Potosí, y para aprovecharse del metal hacían unas formas de barro, del talle y manera que es un albahaquero en España, teniendo por muchas partes algunos agujeros o respiraderos. En estos tales ponían carbón, y el metal encima; y puestos por los cerros o laderas donde el viento tenía más fuerzas, sacaban dél plata, la cual apuraban y afinaban después con sus fuelles pequeños, o cañones con que soplan (...) Llaman a estas formas guaires, y de noche hay tantas dellas por todos los campos y collados, que parecen luminarias; y en tiempo que hace viento recio se saca 
plata en cantidad; cuando el viento falta, por ninguna manera pueden sacar ninguna».

Durante este proceso la ganga se derretía gracias a la acción de fundentes ricos en hierro que facilitaban la separación de la escoria del metal, proceso este último que se complementaba manualmente con una posterior trituración del mismo en los batanes. Dicho procedimiento no sólo es aplicable a la plata sino también al resto de los metales.

La plata desempeñó en los actos religiosos y ceremoniales un papel equiparable al del oro, hallándose incluso combinada con éste en un mismo objeto. Su explotación masiva tuvo lugar a partir del segundo milenio d.C., aunque su empleo en menor escala se remonta casi a tiempos tan antiguos como el oro. Su fácil logro en estado nativo no precisaba de grandes esfuerzos tecnológicos, abundando tanto en la superficie de la tierra como en las menas y en las arenas de los ríos. Cronistas como Cieza de León, entre otros muchos, aporta noticias referidas a las minas de plata, siendo entre ellas famosa la incaica de Porco que se hallaba emplazada cerca de la actual ciudad de Potosí. Al respecto éste nos dice (1984: 372): "Y en este cerro de Porco, que está cerca de la villa de Plata, había minas, donde sacaban plata para los señores; y afirman que mucha de la plata que estaba en el templo del sol de Curicancha fue sacada deste cerro".

En algunas ocasiones durante el proceso de extracción subterránea se solía aplicar fuego a la veta mineralizada, golpeando posteriormente la roca con martillos de piedra e introduciendo cuñas de madera muy dura con objeto de arrancar grandes trozos de mineral que, posteriormente, se molian fuera de la mina antes de proceder a su lavado y concentración en las bateas. Según Rovira (1991: 94), la presencia de frecuentes impurezas de plomo en la composición de este metal, sobre todo a partir del Periodo Intermedio Tardio, sugiere el aprovechamiento progresivo de ciertos minerales fáciles de fundir para lograr su obtención.

Precisamente el proceso de lograr la fusión de metales diferentes para obtener otros ha sido quizá, desde el punto de vista tecnológico, el más difícil de todos. Una de las ventajas que ofrecen dichas uniones metálicas o aleaciones, bien fueran espontáneas o intencionadas, es el hecho de bajar la temperatura de fusión de los metales puros, adquiriendo así éstos mayor consistencia y uniformidad en el proceso de fundición. Parece bastante probable que el origen de las aleaciones pueda haberse hallado en la fundición de menas que contenian naturalmente mezclas de diferentes metales. Entre las más frecuentes empleadas por los antiguos orfebres peruanos fueron la del oro y la plata, la del oro y el cobre, la de la plata y el cobre y, ocasionalmente y sin probable toma de conciencia por parte del orfebre la del oro y el 
platino. La primera surgió (Petersen 1970: 101) como consecuencia de la existencia en el Perú de una amplia gama de oro natural, desde oro de bajo contenido hasta casi puro, suponiendo que el artífice no tuvo que recurrir para lograrla a mezclas intencionadas de difícil elaboración.

El hallazgo de la aleación del oro con el cobre, claramente premeditada y conocida desde el primer milenio a.C., resultó de viltal importancia para el desarrollo orfebre del mundo andino, resultando de ella una mezcla binaria conocida con el nombre de "tumbaga". Ésta permitió una mayor economía del oro, debido a su menor concentración en el objeto, al tiempo que posibilitó, desde el punto de vista simbólico, el logro no de la superposición de éste al cobre sino su íntima incorporación a la esencia misma del objeto, aún cuando la presencia del metal precioso en él se redujera a cantidades mínimas. En opinión de Letchman (1978: 516) "algunos especialistas chimús consiguieron que parecieran de oro láminas de metal hechas con lingotes que contenían sólo un $12 \%$ de oro; el resto de la aleación era fundamentalmente cobre". Otra ventaja importante que ofrece esta mezcla es que las obras fabricadas con ella reproducen mejor los detalles decorativos que las fabricadas con uno solo de los metales. Esta aleación, utilizada masivamente por los orfebres colombianos, contiene en numerosas ocasiones en el Perú una cantidad variable de plata como resultado de las impurezas que suelen aparecer ligadas al oro. La presencia de este tercer componente rebaja aún más la temperatura de fusión del oro con el cobre, posibilitando el logro de una dureza mayor aún que la que posee el bronce fundido. Para este autor (1978: 517) muchos de los objetos de oro que tanto sorprendieron a los primeros españoles llegados a estas tierras, tales como los revestimientos internos de los palacios chimús e incas o el aludido jardín aurífero del Coricancha en el Cuzco, no estuvieron realizados en oro puro sino en una aleación ternaria cobre-plata-oro. Lo mismo sucede con los caracteristicos vasos retrato de estas culturas, aparentemente realizados en plata, que con frecuencia suelen estar realizados con una aleación plata-cobre, ya que la clave del valor de estos objetos parece no haber estado tanto en la proporción del metal noble que contenian como en que éste participara intimamente de su esencia.

Lamentablemente, al hablar de las técnicas orfebres andinas hemos de hacerlo desde un punto de vista genérico ya que salvo algunas herramientas asociadas a un contexto arqueológico - como, por ejemplo, las encontradas en Chile a los que hicimos referencia, o en los yacimientos peruanos de Waywaka, Chotuna o en la tumba de un orfebre chimú en Huarmey- el resto proceden de saqueos de tumbas, pese a lo cual es posible conocer con bastante precisión en qué consistió el proceso de fabricación orfebre. 
Girolamo Benzoni (1989: 322) nos ofrece una detallada descripción de la labor del orfebre ilustrándola con un significativo grabado (Fig. 3). Al respecto nos dice: «Primero, cuando funden el oro y la plata, los meten en un crisol largo o redondo, hecho de un pedazo de tela embadurnada con tierra y carbón triturado. Tras dejarlo secar, lo ponen al fuego con la cantidad de metal que cabe dentro junto con cinco o seis tubos de caña, unas veces más y otras menos, y soplan por ellos hasta que se vuelve líquido. Luego lo sacan, y los orfebres, sentados en el suelo, con unas piedras negras expresamente dispuestas y ayudándose unos a otros, trabajan y hacen o, mejor dicho, hacían en su época de prosperidad, lo que se les había encargado, es decir, estatutas vacias, vasijas, ovejas, joyas y todos los tipos de animales conocidos".



Fig. 3. Descripción del uso de sopladores, martillos y yunques por parte de orfebres prehispánicos. Grabado. Girolamo Benzoni, 1565.

El primer método utilizado en la fabricación de objetos por los orfebres andinos fue el del martillado, consistente en el uso de un yunque, o base de piedra dura, sobre el que se colocaban los nódulos metálicos 
para trabajarlos por medio de un martillo fabricado también en piedra. El resultado de la aplicación de esta técnica fue la obtención de finísimas láminas, facilmente maleables, con las que se construian diferentes objetos tridimensionales tras ser dichas láminas previamente templadas y recortadas. Si el martillado se realizaba sobre un lecho blando, como la arena o sobre un molde de madera, se conseguía, tras templar varias veces la lámina, la elevación de sus paredes, obteniendose así la fabricación de objetos de una sola pieza, técnica que se conoce con el nombre de recopado o embutición profunda (Carcedo 1992: 287). La preferencia por la utilización en el Perú de la técnica del martillado y de la del laminado sobre todas las demás es uno de los caracteres distintivos de su desarrollo orfebre ya desde el inicio de su metalurgia, utilizándose ambas masivamente durante el período chimú e inca en la recubrición de los muros de sus templos y palacios. Este procedimiento hace que el metal cambie de dureza y ductilidad debido a modificaciones durante el proceso en la microestructura del mismo (Petersen 1970: 116), por lo que las láminas resultantes deben ser sometidas una o varias veces al proceso de recocido o templado calentándolas primero en un horno y enfriándolas posterormente en agua para que no pierdan su plasticidad y puedan así seguirse trabajando.

Con objeto de poder unir las láminas y fabricar piezas con volumen los orfebres desarrollaron una compleja técnica de uniones tanto de tipo mecánicas como metalúrgicas. Las primeras incluían el uso de alambres, cintas, clavos, lengüetas y encaje por presión de las partes. Las segundas se realizaban soldando las distintas piezas mediante la aplicación exclusiva de calor o bien mediante éste y la introducción de un metal de relleno que suele resultar casi siempre imperceptible. Una variante de este segundo tipo de uniones con soldante fue la técnica denominada por fusión o granulado consistente en la elaboración de pequeñas bolitas sólidas creadas por la acción del calor a partir de pequeños trozos de una lámina, las cuales el orfebre sitúa en un lugar determinado del objeto adhiéndolas a éste por medio de un pegamento vegetal que, al contacto con el fuego, se quema y las suelda (Carcedo 1992: 295).

Aunque el vaciado no se encuentra entre las técnicas predilectas de los orfebres centroandinos, debido a la escasez de la abeja que producía la cera adecuada para utilizarla en esta técnica, sí que fue conocido y desarrollado por algunas culturas, como en el caso de la Lambayeque o de la Inca. Los moldes empleados en este proceso estuvieron realizados en diversos materiales y fueron de varios tipos, obteniéndose con ellos tanto piezas sólidas como figuras huecas cuyas partes se unian después para componer el objeto. 


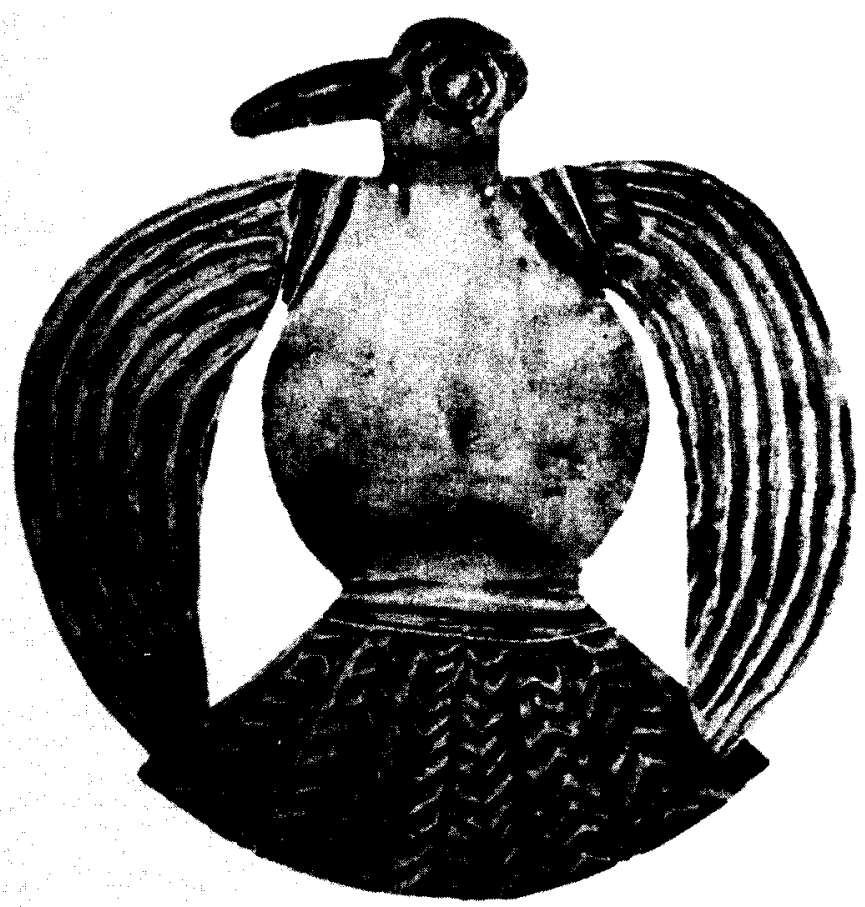

Fig. 4. Adorno con forma de ave. Oro. Cultura Inca. Museo de América. Madrid.

Entre las principales técnicas ornamentales utilizadas por los orfebres destaca la del repujado (Fig. 4), asociada estrechamente al martillado y laminado, mediante la que se consigue realzar la superficie del metal al presionar sobre él con un cincel y un martillo o bien con punzones y buriles, posibilitando así su decoración con grabados en relieve que podían situarse tanto en el anverso como en el reverso de la obra. A esta técnica, masivamente empleada por los orfebres centroandinos, le siguen la de la filigrana, en la que la decoración se realiza por medio de alambres; la engarzada o engastada, cuya ornamentación se realiza con componentes diferentes al metal, como en el caso de los mosaicos realizados con una amplia variedad de conchas y piedras preciosas (Figura 5); la de la incrustación, donde el metal se encuentra taraceado para embutir otro metal diferente; la móvil, constituida por piezas independientes que se unen mecánicamente al objeto; y la pictórica, utilizada con preferencia en las máscaras funerarias mediante la aplicación de polvo de cinabrio. Además de todas éstas los orfebres andinos utilizaron para decorar algunos objetos las plumas de diferentes aves y colores, las cuales, debido a su fragilidad, casi nunca se suelen conservan completas. 


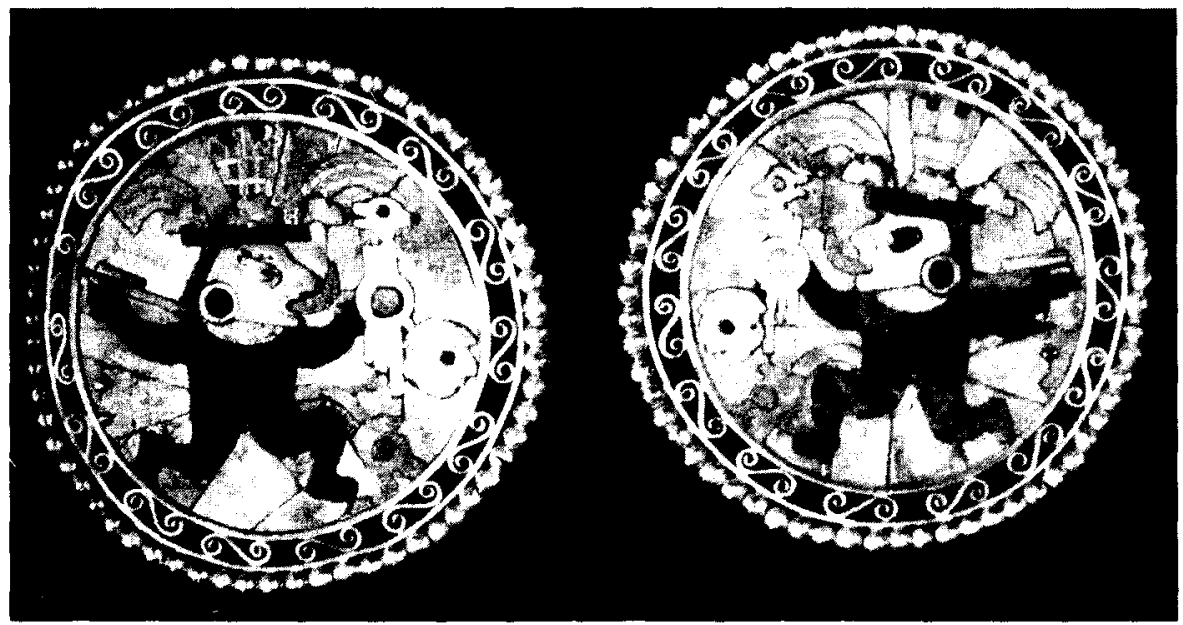

Fig. 5. Orejeras tubulares. Oro y mosaico de lapislázuli, crisocola y concha. Cuitura Mochica. Museo del Oro. Lima.

Por último, dentro de este apartado decorativo merece resaltarse por su importancia la técnica del dorado y del plateado de la superficie de los objetos (Fig. 6). La transformación de la superficie se realizaba mediante dos procedimientos: el primero consistía en la superposición de una capa de oro o de plata sobre cualquier otro metal, bien fuera por medio de la sobrecolocación de una finísima lámina o bien mediante fusión sumergiendo en este último caso al objeto en un baño del metal noble. Según Bray (1991: 61), esta técnica, semejante a nuestro moderno electrochapado, pudo haber comenzado a ser utilizada en el Perú por los orfebres de Vicús, en la costa norte. El segundo procedimiento se conoce con el nombre de dorado por reducción y es aplicable solamente a objetos fabricados a partir de una aleación de oro o de plata con otro metal, es decir de tumbaga, consistiendo éste en la eliminación de la superficie del objeto del componente no deseado para hacer así aflorar el metal noble.

El cronista Gonzalo Fernández de Oviedo (1944: 189) nos relata al respecto "como los indios saben muy bien dorar las pieças é cosas que ellos labran de cobre é de oro muy baxo. Y tienen en esto tanto primor y exçelençia, y dan tan subido lustre á lo que doran, que paresçe que es tan buen oro, como si fuesse de veynte é tres quilates o mas, según la color en que queda de sus manos. Esto haçen ellos con çiertas hiervas, y es tan grande secreto que qualquiera de los plateros de Europa, ó de otra parte, donde entre chripstianos se usasse é supiesse, se ternía por riquíssimo hombre, y en breve tiempo lo sería con esa manera de dorar». La calidad 
y grosor de la capa de oro o de plata conseguida mediante el procedimiento de reducción depende de la temperatura aplicada al objeto y de la duración del tratamiento, así como de la fuerza de las soluciones vegetales o minerales de carácter corrosivo utilizadas durante el mismo.

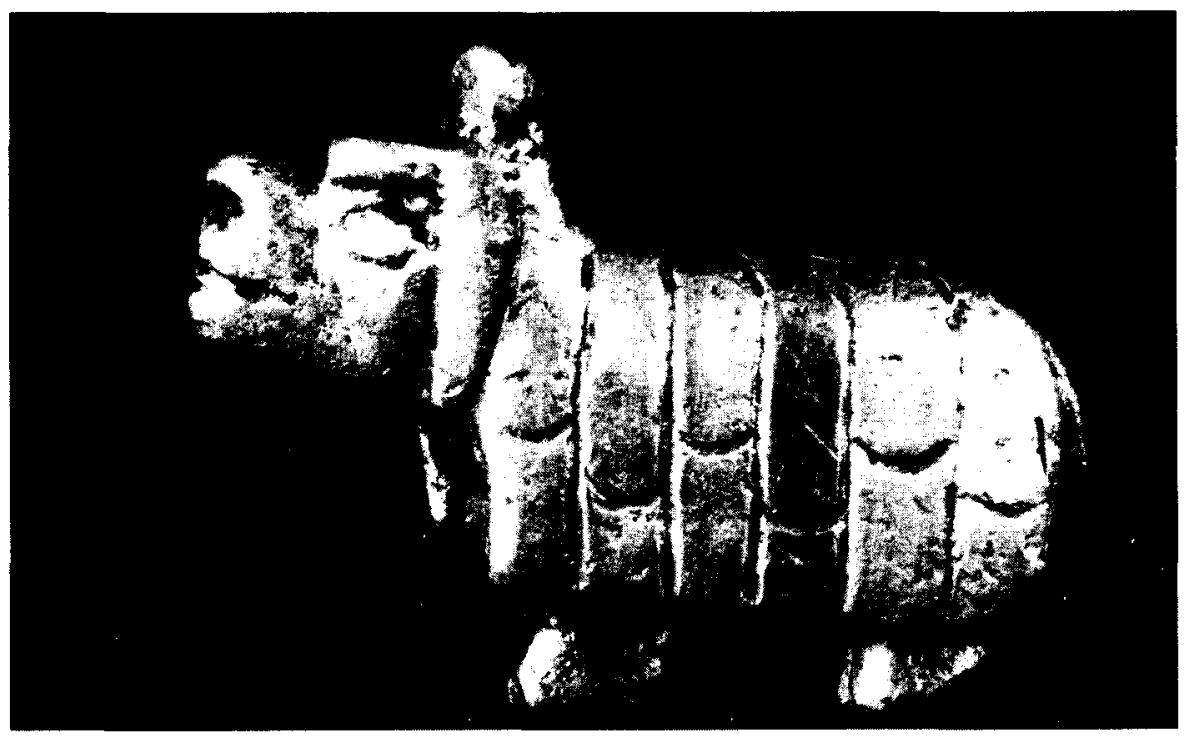

Fig. 6. Figurita zoomorfa. Plata dorada. Cultura Inca. Museo de América. Madrid.

Por último, dado que en estas culturas fue siempre prioritario conseguir una inmejorable apariencia de los objetos fabricados, se procedía al pulido de su superficie para dar el deslumbrante brillo y acabado que tanto maravilló a cuantas personas llegaron a estas tierras procedentes del Viejo Mundo. No debemos olvidar que el virtuosismo patente en la orfebrería inca constituyó tan sólo el último eslabón de una cadena artística iniciada tres mil años antes por anónimos artífices quienes, con su talento artístico y con sus modestos recursos, supieron crear bellas obras cargadas de simbolismo y de espiritualidad. En todas éstas los abstracios y delicados diseños supusieron, más que la expresión de un gusto generalizado por determinadas pautas estéticas, la pervivencia en el incosciente colectivo de una serie de mitos y creencias que se transmitieron, con más o menos variantes, a través de los distintos Períodos u Horizontes en los que se agrupan para su estudio las diferentes culturas indígenas. Dichos artífices, adaptándose tras la Conquista a una nueva cultura totalmente ajena a su cosmovisión, siguieron trabajando con el sudor del Sol y con las lágrimas de la Luna para sus nuevos señores, posibilitando así que perviviera 
su ancestral y artístico oficio pese a las duras condiciones vitales que en ese momento les imponía la historia.

\section{BIBLIOGRAFIA}

ALva, W. (1992): "Orfebrería del Formativo", Oro del antiguo Perú, Banco de Crédito del Perú, págs. 17-116. Lima.

Bray, W. (1991): "La metalurgia en el Perú prehispánico", Los Incas y el antiguo Perú. 3000 años de historia, Sociedad Estatal Quinto Centenario, Tomo I, págs. 58-82. Madrid.

BENzoNi, G. (1989): Historia del Nuevo Mundo, Alianza Editorial, Madrid.

CIEZA DE LEÓN, P. (1984): La crónica del Perú, Historia 16, Madrid.

- (1985): El Señorío de los Incas, Historia 16, Madrid.

CARCEDO P. (1992): "Metalurgia Precolombina: Manufactura y técnicas en la orfebreria Sicán», Oro del antiguo Perú, Banco de Crédito del Perú, Lima.

CARCEDO, P. y SHIMADA, Y. (1985): "Behind the Golden Mask: The Sican gold artifacts from Batan Grande, Perú", Thre Art of Precolumbian Gold, The Jan Mitchell Collection, Wiedenfeld \& Nicolson, págs. 60-75. London.

Cuesta, M. y Rovira, S. (1982): Los trabajos en metal en el área andina, Ministerio de Cultura, Madrid.

FALCHETTI, A.M. (1999): "La orfebrería precolombina. Un largo desarrollo en Colombia y América", El oro y la plata de las Indias en la época de los Austrias, Fundación ICO, Madrid.

Fernández de Oviedo, G. (1851-55): Historia General y Natural de las Indias, Islas y Tierra Firme del Mar Océano, Edición de la Real Academia de la Historia, Madrid.

InCA GaRCllaso de LA VeGa (1943): Cometarios Reales de los Incas, Emecé Editores S.A., Buenos Aires.

Lavalle, J.A. (Director) (1992): Oro del antiguo Perú, Banco de Crédito del Perú, Lima.

LECHTMAN, H. (1978): “Temas de la metalurgia andina», Tecnologia Andina, Instituto de Estudio Peruanos, págs. 489-521. Lima.

LOTHROP, S.K. (1951): "Gold Artifacts of Chavin Style", American Antiquity, Vol. 16, págs. 226240. New Jersey,

- (1978): «Instrumentos para trabajar metales en la Costa Central del Perú", Tecnología Andina, Instituto de Estudios Peruanos, págs. 528-534. Lima.

Pérez de Barradas, J. (1966): Orfebrería prehispánica de Colombia, Banco de la República. Museo del Oro de Bogotá, Madrid.

Petersen, G. (1970): "Minería y metalurgia en el antiguo Perú», Arqueológicas, n. ${ }^{\circ} 12$, Museo Nacional de Antropología y Arqueologia, Lima.

RAvines, R. (Compilador) (1978): Tecnologia Andina, Instituto de Estudios Peruanos, págs. 477-487. Lima.

Rovira, S. (1991): “Metales y aleaciones en el antiguo Perú. Evolución de la tecnología metalúrgica", Los Incas y el antiguo Perú. 3000 años de historia, Sociedad Estatal Quinto Centenario, Tomo I, págs. 82-98. Madrid.

SANCHEZ, E. (1988): Orfebrería precolombina y colonial, Editorial Anaya, Madrid 
